\title{
Drilling Vibration Modes and Penetration Rate Modeling using Artificial Neural Network and Multiple Linear Regression Analysis in Khoman Formation at the Egyptian Western Desert
}

Sherif A. Ezz ( $\nabla$ eng.sherifezz2010@yahoo.com )

Suez University Faculty of Petroleum and Mining Engineering https://orcid.org/0000-0003-3600-8322

Mohamed S. Farahat

Suez Canal University Faculty of Petroleum and Mining Engineering

Said Kamel

Suez Canal University Faculty of Petroleum and Mining Engineering

Ahmed Z. Nouh

Egyptian Petroleum Research Institute

\section{Research Article}

Keywords: Drilling optimization, MATLAB, Neural network, Rate of penetration, Regression, and Vibrations

Posted Date: April 21st, 2021

DOl: https://doi.org/10.21203/rs.3.rs-337955/v1

License: (c) (i) This work is licensed under a Creative Commons Attribution 4.0 International License.

Read Full License 


\title{
Drilling Vibration Modes and Penetration Rate Modeling using Artificial Neural Network and Multiple Linear Regression Analysis in Khoman Formation at the Egyptian Western Desert
}

\author{
Sherif A. Ezz El-Deen ${ }^{1 *}$, Mohamed S. Farahat ${ }^{2}$, Said Kamel $^{2}$, and Ahmed Z. Nouh ${ }^{3}$ \\ $1^{*}$ Corresponding Author: Drilling and Workover Department, Petro Amir Petroleum Company, Cairo, Egypt \\ E-mail: eng.sherifezz2010@yahoo.com \\ 2 Petroleum Engineering Department, Faculty of Petroleum and Mining Engineering, Suez University, Suez, \\ Egypt \\ 3 Petroleum Research Institute, Cairo, Egypt
}

\begin{abstract}
Drill string vibrations are one of the most serious problems encountered while drilling as the bit and drill string interaction with formations under certain drilling conditions usually induces complex shocks and vibrations into the drill string components resulting in premature failure of the equipment and reduced drilling penetration rate. In severe cases where shocks and vibrations accumulated into drill string till exceeded its maximum yield or torsional strength, fatigue will occur and thereby increase the field development costs associated with replacing damaged components, fishing jobs, lost-in-hole situations, and sidetracks. Thus, real-time monitoring for downhole generated vibrations and accordingly adjusting drilling parameters including weight on bit, rotary speed, and circulation rate play a vital role in reducing the severity of these undesirable conditions. Vibration optimization must be done incorporation with the penetration rate, as a minimum economical penetration rate is required by the operator. In this study, three penetration rate and vibration level models were developed for axial, lateral, and stick-slip drilling modes using both MATLAB ${ }^{\mathrm{TM}}$ Software neural network and multiple regression analysis. It is found that the three models' results for vibration level and penetration rate; as compared with those recorded drilling data; showed an excellent match within an acceptable error of average correlation coefficient $(\mathrm{R})$ over 0.95 . The prediction of penetration rate and vibration level is thoroughly investigated in different axial, lateral, and stick-slip vibration drilling modes to be able to best select the optimum safe drilling zone. It is found that the axial vibration could be dampened by gradually increasing the weight on bit and increasing rotary speed while both the lateral and torsional vibrations are enhanced by increasing the rotary speed and decreasing the weight on bit.
\end{abstract}

Keywords: Drilling optimization; MATLAB; Neural network; Rate of penetration; Regression; and Vibrations.

\section{INTRODUCTION}

The ability to monitor and accurately interpret dynamic drilling behavior depends on background knowledge of vibration types and how they arise. Thanks to the new advanced technology, measurement while drilling tools can real-time monitor and detect these generated downhole shocks and vibrations. Thus, we can adjust and optimize drilling parameters based on the type of vibration to minimize nonproductive time, save cost, and enhance drilling efficiency. Appropriate real-time corrective action can have a significant impact on the lifetime of the MWD tool, drill string, motor, bit, drill rates, and whole drilling efficiency [1]. As a matter of fact, to avoid these unstable drilling zones with high vibration levels, we are forced to sacrifice the rate of penetration (ROP) which is the principal goal of drilling economically. So, Optimization is to bypass and diminish vibration with a less harmful impact on ROP. 
Simulation models; built based on actual recorded data with an acceptable minimal error; will help to dispense with the vibration-monitoring MWD tool as drilling parameters in conjunction with drill string design and area experience can be selected, ROP and vibration level could be predicted.

The objective of this study is to develop axial, lateral, and stick-slip models to predict mainly the vibration level and rate of penetration as outputs by using neural network back-forwardpropagation method and multiple linear regression based on previously actual recorded drilling and vibrational data to have the ability to:

- Select and adjust the optimum drilling parameters such as weight on bit, rotational speed, and mudflow rate.

- Enhance the drilling efficiency and avoid drill string twist-off.

- Minimize the cumulative drilling cost by reducing NPT.

- Give minimal error outputs compared to the MWD tool readings.

Downhole vibrations are generally classified into three primary categories, axial, torsional, and lateral/transverse as shown in Fig. 1.

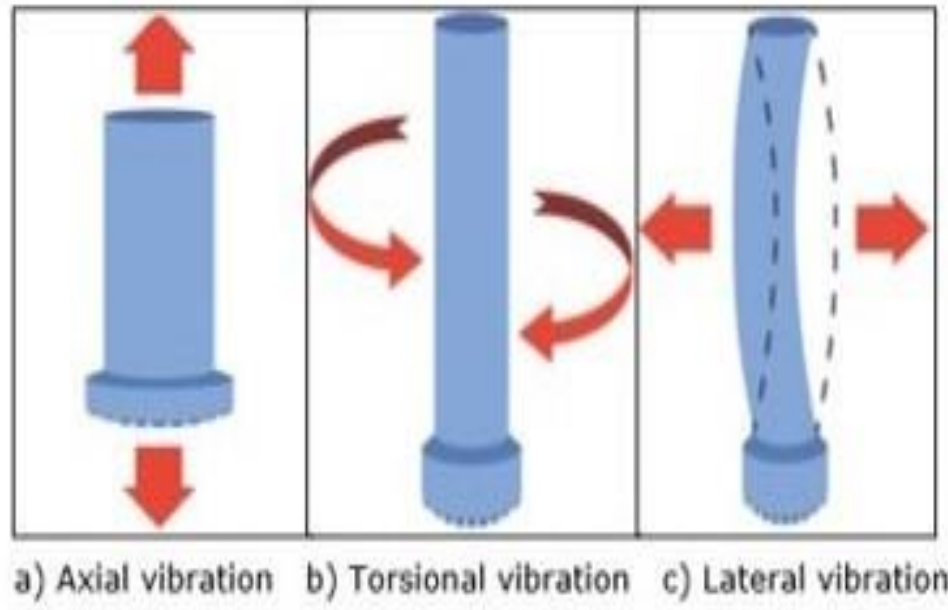

Fig. 1- Vibration modes a) Axial vibration b) Torsional vibration c) Lateral vibration

\section{Axial vibration}

Vibrations that propagate in a parallel direction to the axis of the drill string. Axial vibrations are caused by the movement of the drill string, upwards and downwards, and may result in a bit bounce. Bit bounce is observed when the changes in substantial bit weight (WOB) cause the bit to periodically rise off the bottom, along the drill string in a vertical direction, and then drop and affect the formation $[2,3]$.

\section{Torsional vibration}

Torsional vibrations usually occurred as a result of excessive twisting motions in the drill string. Stick-slip is the primary mechanism for creating torsional vibrations. Due to the frictional torque of bit and BHA, the vibration is generated by cyclic acceleration and deceleration of bit and drill string [2,3].

\section{Lateral vibration}

Lateral vibrations are those vibrations formed in a direction perpendicular to the string. The main source of vibration is a whirl, which is the eccentric rotation of the drill string, around a point 
other than the center of the borehole. Transverse vibrations are approved to be the most damaging process, resulting in significant damage to the BHA components and wellbore [2,3].

\section{LITERATURE REVIEW}

Over the past years, several mathematical models have been proposed to explain the relationship between the rate of penetration and drilling parameters such as weight on bit, rotary speed, circulation rate, and formation rock mechanics neglecting the impact of vibration data. In the following, some of the well-known models are briefly discussed.

Maurer et al. [4] present an equation relating the ROP with WOB, RPM, bit size, and rock strength as expressed in Eq. 1:

$\mathrm{ROP}=\frac{K N\left(W-W_{0}\right)^{2}}{d_{b}^{2} S^{2}}$

Where ROP refers to the rate of penetration $\mathrm{ft} / \mathrm{hr} ; \mathrm{K}$ is a constant of proportionality, $\mathrm{S}$ denotes the rock compressive strength, psi; $\mathrm{W}$ is the $\mathrm{WOB}, \mathrm{lbf} ; \mathrm{W}_{0}$ is the threshold $\mathrm{WOB}, \mathrm{lbf} ; \mathrm{d}_{\mathrm{b}}$ is the bit diameter, in; and $\mathrm{N}$ denotes the rotary speed, rpm.

Bingham [5] proposes an experimental model that is applicable for low values of weight on bit (WOB) and rotational speed (RPM). This model neglects the effect of drilling depth. The Bingham model is defined by

$\mathrm{ROP}=\mathrm{K}\left(\frac{W O B}{d_{b}}\right)^{a 5} N^{e}$

Where $\mathrm{K}$ is a proportionality constant, as denotes the weight on bit exponent that should be determined experimentally based on the prevailing conditions.

Bourgoyne and Young [6] develop a model with nine inputs (depth, equivalent mud density, equivalent circulation density, WOB, bit size, rotational speed, $\mathrm{Q}$, mud density, plastic viscosity) but multiple regressions are required to calculate seven different exponents for this model.

Recently, and with the help of progressing neural network modeling method, numerous models were built for ROP prediction using drilling data. Abdolali Esmaeili et al. [7] develops an ROP model using neural network and drill string vibration data.

As it is realized from previous works of literature, most of the models just illustrate the relationship between penetration rate and drilling parameters such as weight on bit, rotary speed, bit diameter, mud weight, and formation rock mechanics except Abdolali Esmaeili neural network model which takes into consideration the effect of vibration data on the rate of penetration.

In this approach, we built three models for the rate of penetration and drill string vibration level independently using neural network and multiple linear regression taking into consideration the type of vibration; axial, lateral, or stick-slip; and vibration level which helps to define the optimum safe drilling zone as a combination between a high rate of penetration and low vibration level for each vibration mode.

\section{Data used}

The real data used in this study were collected from different fields in the western desert of Egypt including 12.25" hole drilling parameters and vibrational data, especially those encountered at Khoman formation with high downhole axial, lateral, and stick-slip vibration levels to be able to understand the drilling behavior and best select the stable drilling zone. 
Fig. 2. shows the weight on bit and rotational speed relationship for each vibration mode axial, lateral, and stick-slip. Detecting a stable drilling zone for the whole section would be so difficult, ut step-by-step real-time drilling parameters optimization is the best choice for safe drilling practice.

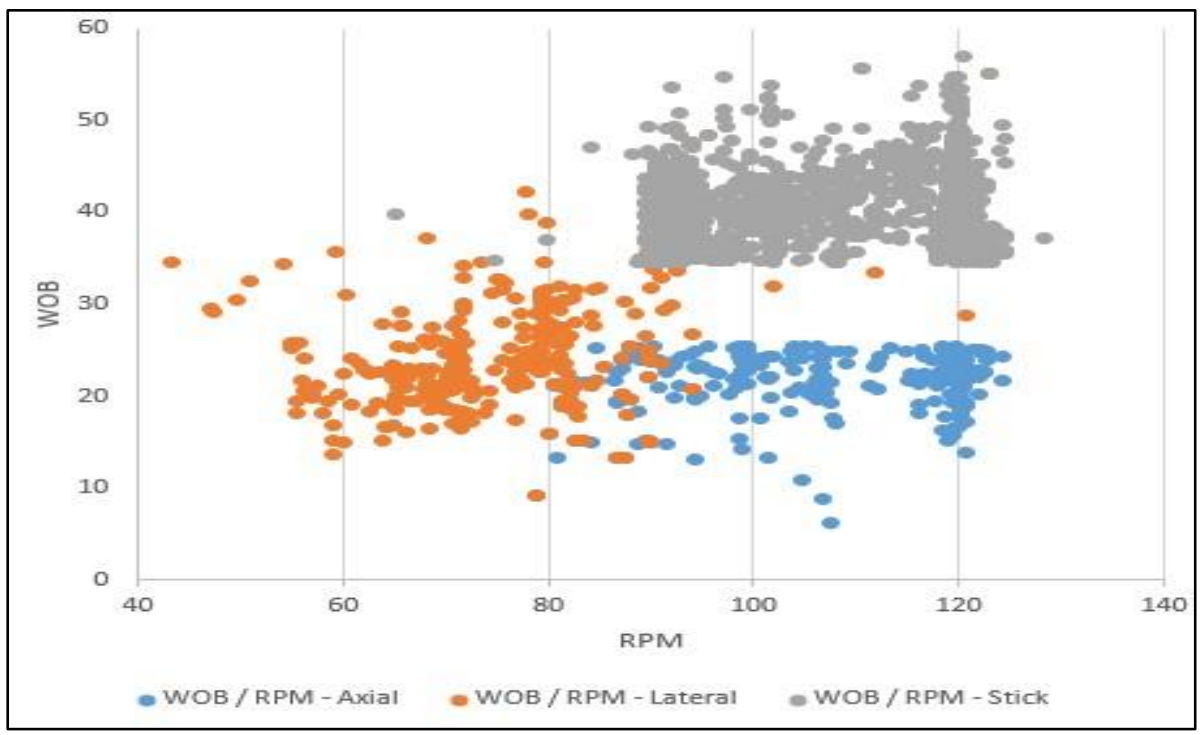

Fig. 2- WOB / RPM relationship

\section{METHODOLOGY AND MODEL DESCRIPTION}

\subsection{ANN Model Development}

To build the artificial neural network model for ROP and vibration level prediction, the model passed through 3 stages as follows [8]:

- Data preprocessing,

- Model learning,

- Model evaluation.

\section{Data Preprocessing}

Table 1. illustrates the real field input data ranges for axial, lateral, and stick-slip ANN models. Eight data sets as input parameters across 20 wells, including the depth, WOB, RPM, TQ, standpipe pressure (SPP), the flow in (GPM), DWOB, and MSE. The output data would be the rate of penetration and the vibration level.

The whole input data were collected from the mud logging unit except for the values of downhole weight on bit (DWOB), as measured from the sensor at the MWD tool and mechanical specific energy (MSE); which is an indicator for the amount of energy transfer from the surface to bit [9]; is calculated as per Eq. 3

MSE $=E_{m} \times\left(\left(\frac{480 \times \mathrm{TQ} \times \mathrm{RPM}}{\mathrm{d}_{\mathrm{bit}}{ }^{2} \times R O P}\right)+\left(\frac{4 \times \mathrm{WOB}}{\pi \mathrm{d}_{\mathrm{bit}}{ }^{2}}\right)\right)$

Where MSE refers to mechanical specific energy (psi), $\mathrm{E}_{\mathrm{m}}$ denotes bit mechanical efficiency (assumed to be 0.35).

\section{Model Learning}

The algorithm of backpropagation in neural networks comprises the following sequence [10]:

- Initialize the number of hidden nodes. 
- Initialize the learning rate and the maximum number of iterations (set all weights and thresholds to small random values).

- Select the activation function, which interconnects the input neuron to its output by a mathematical equation.

- Input values for the hidden nodes are determined based on Eq. 4.

$\mathbf{S}_{\mathrm{j}}=\sum_{\mathrm{i}=\mathbf{1}}^{\mathrm{n}} \mathbf{X}_{\mathrm{i}} \mathbf{W}_{\mathrm{ij}}$

Where $\mathbf{X}_{\mathbf{i}}$ is the input variable at node $\mathrm{i}$ and $\mathbf{W}_{\mathbf{i j}}$ is the weight from input node $\mathrm{i}$ to hidden node $\mathrm{j}$.

The output was derived from the hidden nodes, according to Eq. 5:

$Y_{j}=f\left(S_{j}\right)=\frac{1}{1+e^{-S_{j}}}$

Where $\mathbf{Y}_{\mathbf{j}}$ is the output variable from hidden node $\mathbf{j}$. The same algorithm was employed to calculate the inputs to the output nodes.

- The error term for the output node was calculated.

- Iteration ending condition was defined when the network errors were larger than the pre-defined threshold or the number of iterations was less than the maximum preset iterations, then the calculation process continued till one of these criteria was achieved.

In this study, simple axial, lateral, and stick-slip three-layered ANN networks (one input layer, one hidden layer, and one output layer) were created by programming software MATLAB ${ }^{\mathrm{TM}}$. Cross-validation plots were applied to determine the most proper number of neurons in the hidden layer.

Weights and biases of the networks were then appropriately initialized, and therefore the artificial neural networks were subjected to a backpropagation training algorithm [11]. ANN training involves the use of $70 \%$ of the original data sets, and the last $30 \%$ of the original data sets are allocated for model verification and testing.

\section{Artificial Neural Training}

The ANN models were trained by the backpropagation method with a learning rate of 0.001 . Tables (2, 3, and 4) show neural network parameters for axial, lateral, and stick-slip models, respectively. Figures (3, 4, and 5) present the network structure of the proposed ANN axial, lateral, and stick-slip models used in this study, respectively.

\section{Table 1-}

Input data ranges for axial, lateral, stick-slip ANN models

\begin{tabular}{|c|c|c|c|c|c|c|c|c|c|}
\hline \multirow{2}{*}{ No. } & \multirow{2}{*}{ Input parameter } & \multirow{2}{*}{$\begin{array}{l}\text { Data } \\
\text { Source }\end{array}$} & \multicolumn{2}{|c|}{ Axial } & \multicolumn{2}{|c|}{ Lateral } & \multicolumn{2}{|c|}{ Stick-slip } & \multirow{2}{*}{ Unit } \\
\hline & & & Min & $\operatorname{Max}$ & Min & Max & Min & $\operatorname{Max}$ & \\
\hline 1 & Depth & 1 & 2785 & 6785 & 3660 & 5805 & 2750 & 6775 & Feet \\
\hline 2 & Weight on Bit & $\stackrel{!}{=}$ & 6 & 25 & 13 & 47 & 35 & 61 & Klbs \\
\hline 3 & $\begin{array}{l}\text { Revolution per } \\
\text { minute }\end{array}$ & $\begin{array}{l}\Xi \\
00 \\
.0\end{array}$ & 71 & 124 & 55 & 118 & 65 & 128 & RPM \\
\hline 4 & Torque & $\stackrel{800}{=}$ & 2 & 14 & 9 & 14.5 & 2 & 11 & Klbs.ft \\
\hline 5 & Standpipe pressure & $\stackrel{s}{\Sigma}$ & 543 & 2096 & 526 & 1685 & 421 & 2140 & Psi \\
\hline 6 & Flow in & 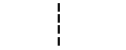 & 297 & 649 & 242 & 623 & 234 & 658 & GPM \\
\hline 7 & $\begin{array}{c}\text { Downhole Weight } \\
\text { on Bit }\end{array}$ & $\begin{array}{l}\text { MWD } \\
\text { sensor }\end{array}$ & 3 & 22 & 8 & 41 & 20 & 51 & Klbs \\
\hline
\end{tabular}




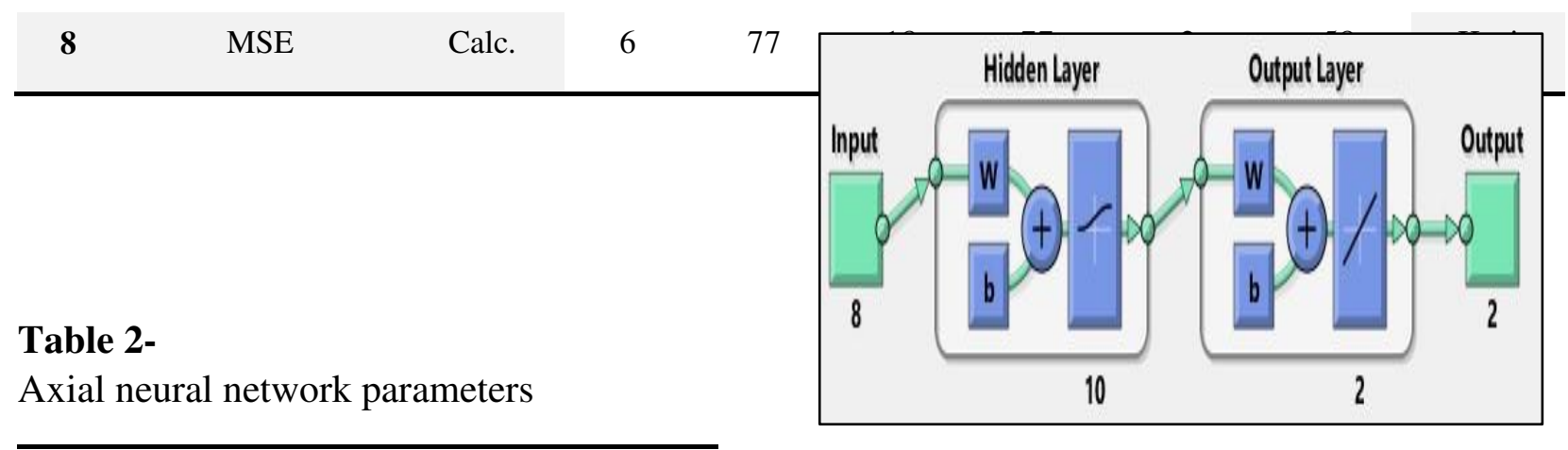

\begin{tabular}{lc}
\hline Network structure & ANN parameter \\
\hline Input layer neurons & 8 \\
Output layer neurons & 2 \\
Hidden laver & 1
\end{tabular}

Table 3-

Lateral neural network parameters $\quad \begin{aligned} & \text { 'g- } \\ & \text { ar }\end{aligned}$ Learning rate $\quad 0.001$

\begin{tabular}{|c|c|}
\hline Network structure & ANN parameter \\
\hline Input layer neurons & 8 \\
\hline Output layer neurons & 2 \\
\hline Hidden layer & 1 \\
\hline Hidden layer neurons & 10 \\
\hline $\begin{array}{l}\text { Table 4- } \\
\text { Stick-slip neural netv }\end{array}$ & $\begin{array}{ll}\text {,g-Sig) } \\
\text { ar }\end{array}$ \\
\hline
\end{tabular}

\begin{tabular}{lc}
\hline Network structure & ANN parameter \\
\hline Input layer neurons & 8 \\
Output layer neurons & 2 \\
Hidden layer & 1 \\
Hidden layer neurons & 10 \\
Activation function & Sigmoid (Log- \\
Learning rate & Sig) \& Linear \\
& 0.001 \\
\hline
\end{tabular}

Mo Fig. 5- Stick-slip proposed ANN model architecture $\left(\right.$ Generated by MATLAB ${ }^{\mathrm{TM}}$ )

The accuracy of the neural network model is e C. data through several statistical error analysis including average absolute percent relative error (AAPRE), Mean squared error (MSE), Root mean squared error (RMSE), and Standard deviation (SD) $[12,13]$.

\section{Garson Algorithm}

Garson et al. $[14,15]$ used the connection weights in the ANN architecture to assess the desired relative importance of each variable. The relative importance for each variable is given by the following formula: 


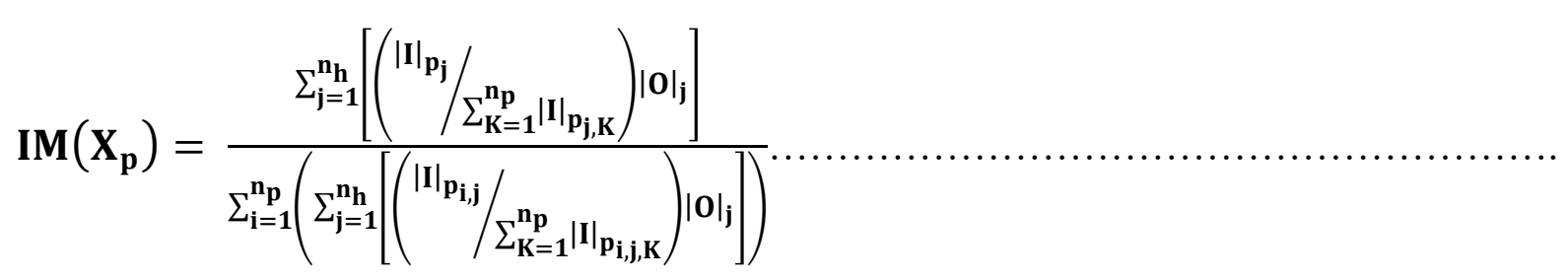

Where $\mathbf{I M}\left(\mathbf{X}_{\mathbf{p}}\right)$ represents the relative importance measure of the input variable $P$ th on the output. $\mathbf{n}_{\mathbf{p}}$ is the number of input parameters and $\mathbf{n}_{\mathbf{h}}$ is the number of neurons in the hidden layer. The term $|\mathbf{I}|_{\mathbf{p}_{\mathbf{j}}}$ is the absolute value of the weight in the neural network for the $P$ th input variables and Jth hidden layer. The term $|\mathbf{0}|_{\mathbf{j}}$ is the absolute value of the output layer weight in the neural network for the $J$ th hidden layer.

\subsection{Multiple Linear Regression Analysis}

Multiple linear regression is a statistical method of data analysis to estimate the relationship between two or more independent variables and one dependent variable. Eq. 7 shows the basic model relationship:

$Y_{i}=\beta_{0}+\beta_{1 i} X_{1}+\beta_{2 i} X_{2}+\beta_{2 i} X_{2}+\cdots+\beta_{k} X_{k i}+\epsilon_{i}$

Where $\boldsymbol{Y}_{\boldsymbol{i}}$ is the dependent variable, and there are $\mathrm{k}$ of independent variables $\left(x_{1}, x_{2}, \ldots . x_{k}\right) . \boldsymbol{\beta}_{\mathbf{0}}$ and $\boldsymbol{\beta}_{\boldsymbol{k}}$ are the intercept and slope parameters. $\boldsymbol{\epsilon}_{\boldsymbol{i}}$ is the error term, and $i=1 \ldots n$ refers to the total number of observations [16].

In this study, two regression models for each vibration mode; axial, lateral, and stick-slip; were developed in which the rate of penetration (ROP), vibration level represent the dependent variables and the depth, WOB, RPM, TQ, SPP, GPM, DWOB, MSE represent $\left(\mathrm{x}_{1} \ldots . \mathrm{x}_{8}\right)$ the independent variables. The estimated coefficients and intercept were selected to minimize the sum of squared errors.

Once a multiple linear regression model was formed, A regression report is typically outlined. With the help of estimated coefficients and statistical data, the strength of the model can be verified. A parametric sensitivity analysis is performed later on each model by increasing and decreasing some variables by $10 \%$ to find out which parameters have a greater impact on the ROP and vibration level.

Table 5 displays the regression statistics results and the estimated coefficients for both ROP and vibration level models in the axial, lateral, and stick-slip drilling modes.

\section{RESULT AND DISCUSSION}

\section{ANN model structure}

The ANN total data set was divided into three data sets: training set, validation set, and testing set. More specifically, 30\% of the whole dataset was randomly selected as the testing and validation sets, and then utilized for comparison between the proposed ANN model results and actual recorded data.

Fig. $(6,7$, and 8$)$ shows the prediction results of regression analysis for training, validation, testing, and total data set related to axial, lateral, and stick-slip models, respectively. It is observed that the difference in the correlation coefficient $(\mathrm{R})$ between training and testing data sets for all models is relatively small, which indicates that these ANN models' training process is reliable.

Moreover, it can be observed that the predicted rate of penetration and vibration level have a good match with the target values with an acceptable range of accuracy. The $\mathrm{R}$ of the testing data set for all models is estimated to be around 0.95 indicating that these ANN models have relatively strong predictive behavior. 
Table 5-

ROP \& Vibration regression statistics and coefficients

\begin{tabular}{|c|c|c|c|c|c|c|c|}
\hline \multirow{2}{*}{\multicolumn{2}{|c|}{ Parameter }} & \multicolumn{3}{|c|}{ ROP Regression Model } & \multicolumn{3}{|c|}{ Vibration Regression Model } \\
\hline & & Axial & Lateral & Stick-slip & Axial & Lateral & Stick-slip \\
\hline \multicolumn{2}{|c|}{ Multiple R } & 0.926728 & 0.9084 & 0.88471127 & 0.908693 & 0.720211 & 0.8927944 \\
\hline \multicolumn{2}{|c|}{ R Square } & 0.858826 & 0.825191 & 0.78271403 & 0.825724 & 0.518704 & 0.7970818 \\
\hline \multicolumn{2}{|c|}{ Adjusted R Square } & 0.852551 & 0.819364 & 0.78061971 & 0.817978 & 0.370612 & 0.795126 \\
\hline \multicolumn{2}{|c|}{ Standard Error } & 6.127561 & 2.630403 & 8.63204927 & 0.377199 & 0.303361 & 0.2828931 \\
\hline \multicolumn{2}{|c|}{ Observations } & 189 & 249 & 839 & 189 & 35 & 839 \\
\hline \multicolumn{8}{|c|}{ Coefficients } \\
\hline Intercept & (X0) & 16.93501 & 0.648517 & 22.9482996 & -1.87064 & 3.482601 & 4.4615572 \\
\hline Depth & (X1) & -0.00207 & 0.00045 & 0.00534881 & 0.000204 & -0.0001 & $9.315 \mathrm{E}-05$ \\
\hline WOB & $(\mathrm{X} 2)$ & -1.58102 & 0.493951 & -2.3755313 & -0.00634 & 0.049479 & -0.005993 \\
\hline RPM & (X3) & 0.268227 & 0.215426 & 0.34981771 & 0.019703 & -0.03226 & -0.000143 \\
\hline TORQ. & (X4) & 0.003179 & 0.001963 & 0.00235017 & 0.000413 & 0.000156 & $3.039 \mathrm{E}-05$ \\
\hline SPP & (X5) & -0.00117 & 0.004695 & -0.0103191 & $-8.5 E-05$ & 0.001257 & -0.000366 \\
\hline FLOW IN & (X6) & 0.014828 & -0.00862 & -0.0006879 & 0.000375 & -0.00467 & -0.00463 \\
\hline DH WOB & (X7) & 1.891414 & -0.46128 & 2.44481598 & -0.0125 & -0.03314 & 0.0095891 \\
\hline MSE & (X8) & -0.75143 & -0.49127 & -0.8780216 & -0.00299 & 0.005036 & -0.006303 \\
\hline
\end{tabular}

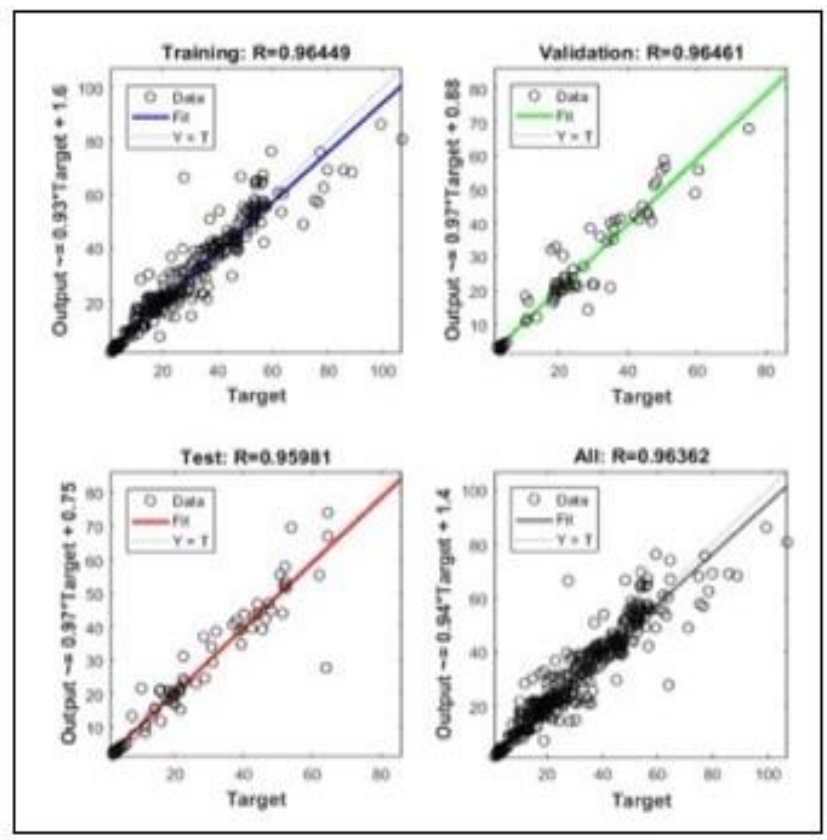

Fig. 6- Regression for Axial proposed ANN model (Generated by MATLAB ${ }^{\mathrm{TM}}$ )
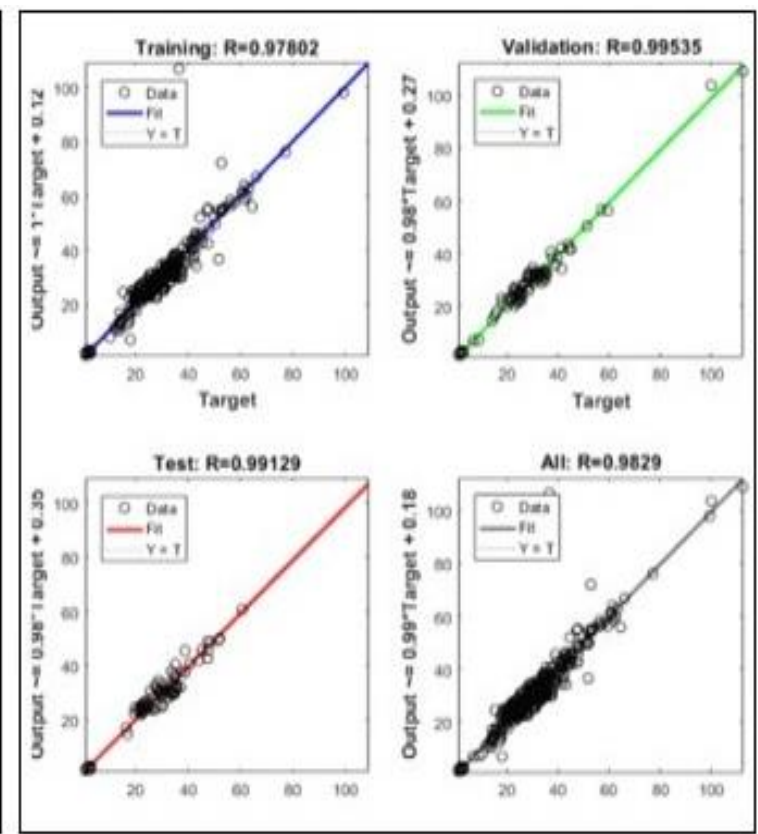

Fig. 7- Regression for Lateral proposed ANN model (Generated by MATLAB ${ }^{\mathrm{TM}}$ )

\section{Modeling analysis}

Table 6 presents the relative importance of various input parameters; as per garthon formula calculations; on the rate of penetration and vibration level outputs from axial, lateral, and stickslip ANN models. These results indicate that each input plays a great role according to each input weight, therefore optimizing the drilling process through controlling vibration level severity with little harmful impact on the rate of penetration. 


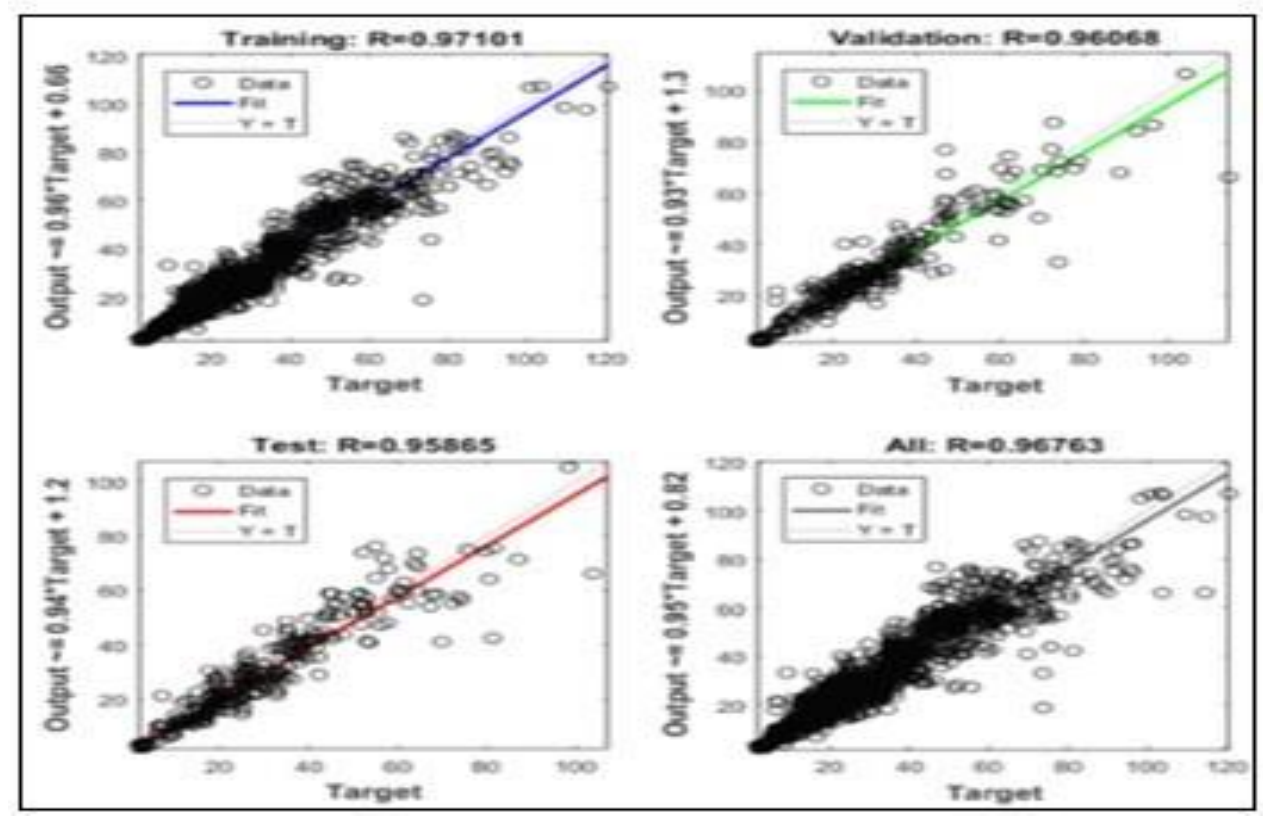

Fig. 8- Regression for Stick-slip proposed ANN model (Generated by MATLAB ${ }^{\mathrm{TM}}$ )

Table 6-

Relative importance of various input parameters in ANN models

\begin{tabular}{ccccc}
\hline \multirow{2}{*}{$\#$} & \multirow{2}{*}{ Parameters } & \multicolumn{3}{c}{ Relative Importance \% } \\
\cline { 3 - 5 } & & Axial & Lateral & Stick-slip \\
\hline 1 & Depth & $9.3 \%$ & $10.1 \%$ & $5.9 \%$ \\
2 & WOB & $3.3 \%$ & $7.1 \%$ & $7.2 \%$ \\
3 & RPM & $14.6 \%$ & $27.2 \%$ & $10.9 \%$ \\
4 & TORQ. & $22.2 \%$ & $7.8 \%$ & $21.9 \%$ \\
5 & SPP & $4.5 \%$ & $7.2 \%$ & $4.1 \%$ \\
6 & Flow in & $10.6 \%$ & $11.6 \%$ & $13.6 \%$ \\
7 & DH WOB & $6.3 \%$ & $7.9 \%$ & $8.0 \%$ \\
8 & MSE & $29.1 \%$ & $21.0 \%$ & $28.3 \%$ \\
\hline
\end{tabular}

Tables $(7,8)$ demonstrate a more comprehensive set of error calculations for the modeled regression-neural ROP, and vibration level results in axial, lateral, and stick-slip drilling modes. As can be seen that all error statistical values are small which confirms the reliability of both neural and regression model results.

\section{Table 7-}

Regression and neural ROP models error calculation

\begin{tabular}{|c|ccc|ccc|}
\hline \multirow{2}{*}{ Parameter } & \multicolumn{3}{|c|}{ Regression ROP } & \multicolumn{3}{c|}{ Neural ROP } \\
\cline { 2 - 7 } & Axial & Lateral & Stick-slip & Axial & Lateral & Stick-slip \\
\hline MSE & 32.2719 & 4.95589 & 79.2959249 & 17.1506 & 0.0785 & 0.046767 \\
RMSE & 5.68084 & 2.22618 & 8.90482593 & 4.14133 & 0.28018 & 0.2162568 \\
AAPRE \% & 10.9171 & 7.26036 & 19.0695773 & 7.0563 & 0.72482 & 0.4327411 \\
SD & 0.15789 & 0.09657 & 0.25026054 & 0.10842 & 0.01175 & 0.0091985 \\
\hline
\end{tabular}


Table 8-

Regression and neural vibration models error calculation

\begin{tabular}{|c|ccc|ccc|}
\hline \multirow{2}{*}{ Parameter } & \multicolumn{3}{|c|}{ Regression Vibration } & \multicolumn{3}{c|}{ Neural Vibration } \\
\cline { 2 - 7 } & Axial & Lateral & Stick-slip & Axial & Lateral & Stick-slip \\
\hline MSE & 0.17403 & 0.19722 & 0.07712291 & 1.30369 & 0.29578 & 0.0401002 \\
RMSE & 0.41717 & 0.44409 & 0.27771012 & 1.14179 & 0.54386 & 0.2002505 \\
AAPRE \% & 10.0791 & 17.523 & 8.96420062 & 27.7601 & 14.1371 & 3.766567 \\
SD & 0.1359 & 0.3204 & 0.10827111 & 0.42918 & 0.27279 & 0.069284 \\
\hline
\end{tabular}

\section{ROP Vs. depth}

Fig. 9 illustrates the relationship between regression, neural modeled, and actual ROP results with depth for all axial, lateral, and stick-slip vibration drilling modes. Moreover, the predicted values for both neural and regression ROP models showed a very good match with actual values with an acceptable minimal error. The neural network model has more consistent results than the regression model with the actual recorded values.

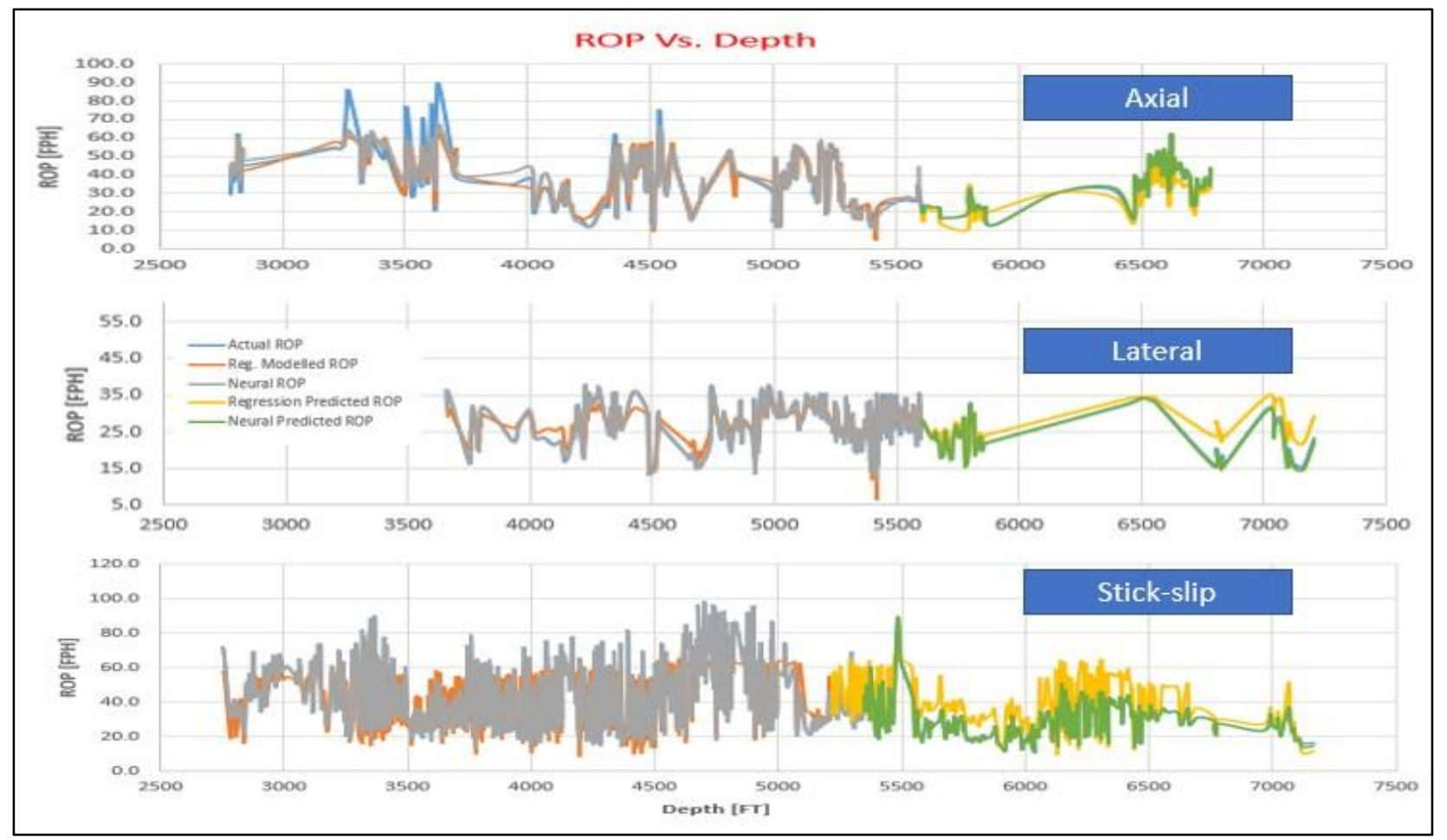

Fig. 9- ROP neural, regression and actual vs. depth

\section{Vibration Vs. depth}

Fig. 10 illustrates the relationship between regression, neural modeled, and actual vibration level results with depth for all axial, lateral, and stick-slip vibration drilling modes. The integrity and combination of penetration rate and vibration level results can help to best select the suitable safe drilling behavior.

\section{Parametric sensitivity analysis}

A parametric sensitivity analysis is applied to determine the most influential operational drilling parameters on the regression developed ROP and vibration models. The analysis is 
performed on the models which were developed using the multiple regression analysis for axial, lateral, and stick-slip drilling modes. The weight on bit, revolutions per minute, and torque are increased and reduced by $10 \%$ separately. A combination set of $10 \%$ increasing and decreasing is applied on standpipe pressure and circulation rate commingle. Finally, a combination set of $10 \%$ weight on bit increase in conjunction with $10 \%$ revolutions per minute decrease, then compared with $10 \%$ weight on bit decrease in conjunction with $10 \%$ revolutions per minute increase.

As shown in Fig. 11: In the axial mode, the best optimization parametric set which generates less vibration level with little harmful impact on ROP is increasing WOB and decreasing RPM. In the lateral and stick-slip modes, the best optimization parametric set which generates less vibration level with little harmful impact on ROP is increasing RPM and decreasing WOB.

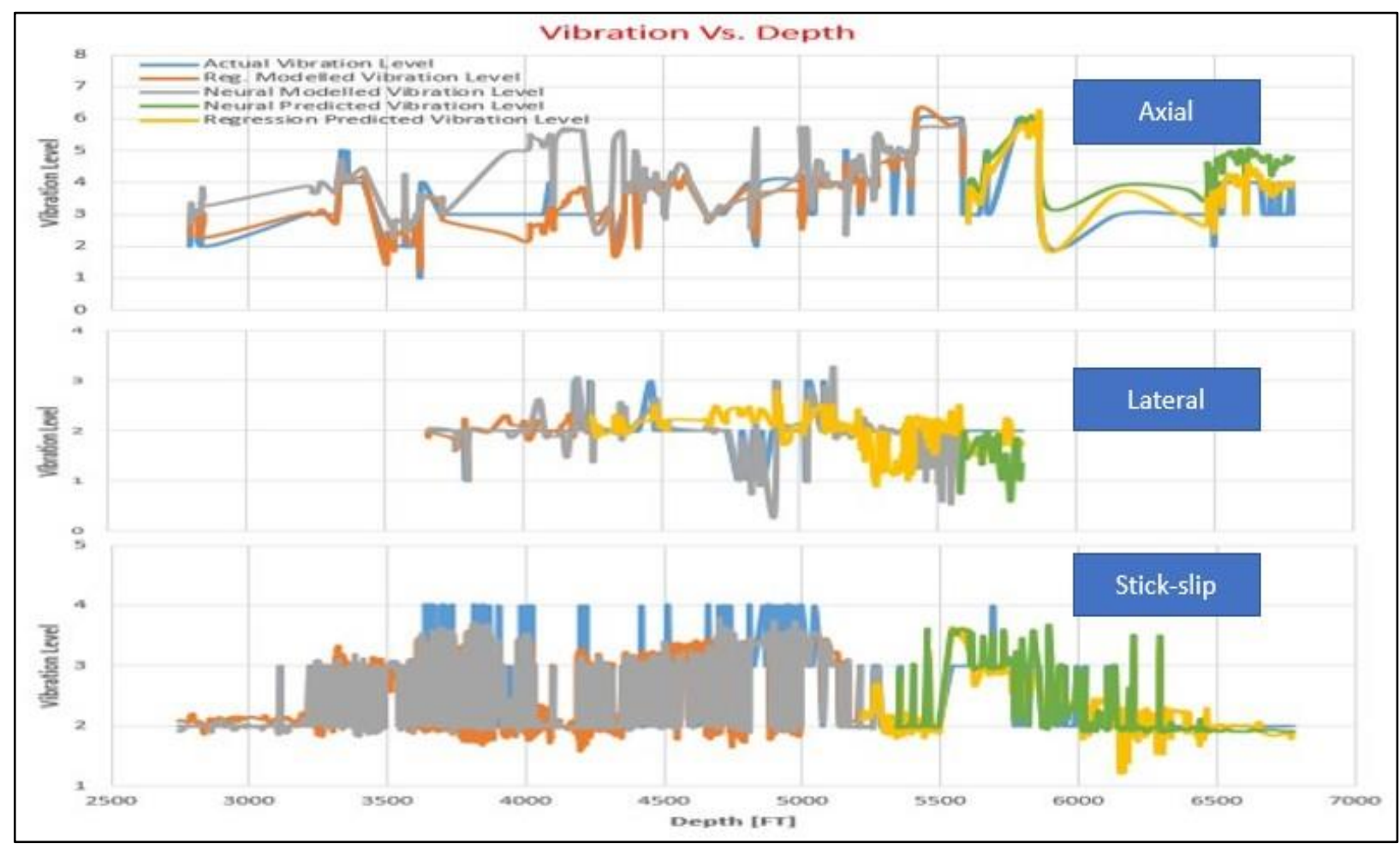

Fig. 10- Vibration neural, regression and actual vs. depth

\section{Conclusion}

Utilization of the ANN approach through MATLAB ${ }^{\mathrm{TM}}$ software and multiple regression analysis for predicting the vibration level and the rate of penetration in axial, lateral, and stick-slip drilling modes have been investigated in the present study.

For any planned combination set of drilling parameters (i.e. WOB, RPM, GPM, TQ), Realtime checking the expected type and severity of vibration accompanying with resulting penetration rate could be achieved, and hence based upon models results, we can readjust the drilling parameters to be in the optimum safe drilling zone.

Real-time monitoring of vibration type and penetration rate will reduce the risk of exceeding the drill string manufacture yield or torsional limit and so avoid drill string twist-off. Routine inspection and very good tracking for the drill string components working conditions and environment history will help to diminish the cases of abrupt fatigue.

Modeling usually provides an effective solution to give reliable simulated results compared with those obtained from measurement while drilling (MWD) data which saves cost and enhances drilling efficiency. 
Drilling parameters play the primary role in determining the vibration type and level in addition to affecting the rate of penetration as follows:

- Axial vibration mode is dampened by gradually increasing WOB and decreasing RPM.

- Lateral vibration mode is associated with a whirl, bending of the drill string, decrease in $\mathrm{ROP}$, and requires immediate action through decreasing RPM and monitor the effect on torque and ROP.

- Stick-slip usually occurred while drilling with a tri-cone bit is due to drill string and wellbore contact. So, an excellent drill string design and placement of stabilizers will have a good impact on the vibration, therefore the drilling efficiency.

In future work, applying different types of bits other than rock bit in addition to mud properties in order to spread out the applications of developed models in different areas.

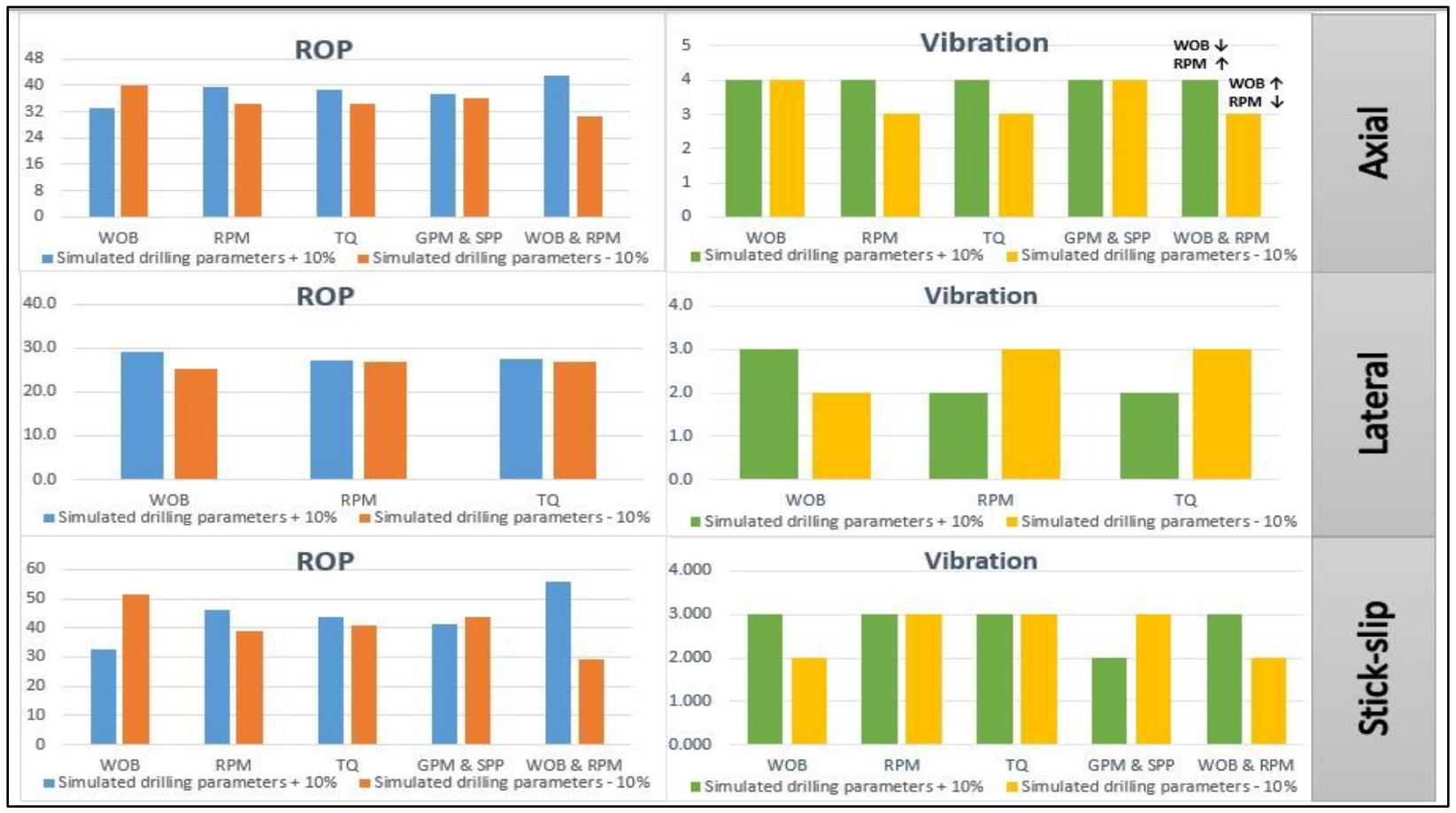

Fig. 11- ROP and vibration parametric sensitivity analysis

\section{NOMENCLATURE}

ANN Artificial neural network

DWOB Downhole weight on bit, [klbs]

GPM Gallons per minute

MSE Mechanical specific energy, [psi]

MWD Measurement while drilling

$\begin{array}{ll}\text { ROP } & \text { Rate of penetration, [feet per hour] } \\ \text { RPM } & \text { Revolutions per minute } \\ \text { SPP } & \text { Standpipe pressure, }[\mathrm{psi}] \\ \text { TQ } & \text { Torque, [klbs.ft] } \\ \text { WOB } & \text { Weight on bit, [klbs] }\end{array}$

ROP Rate of penetration, [feet per hour]

Ethics Approval

I hereby confirm all the ethics approval principles including (Honesty, Objectivity, Integrity, Carefulness, Openness, Respect for Intellectual Property, Confidentiality, Responsible Publication, Responsible Mentoring, Respect for Colleagues, Social Responsibility, NonDiscrimination, Competence, Legality, Human Subjects Protection...etc.). 


\section{Consent to participate/ publication}

I approve and ready to participate and publish in your esteemed journal.

\section{Availability of data and material}

All data are available and under your request.

\section{Declaration of Competing Interest}

The authors declare that they have no known competing financial interests or personal relationships that could have appeared to influence the work reported in this paper.

\section{REFERENCES}

[1] Baker Hughes, "Vibration Stick-Slip ( VSS ) User's Guide", January, 1999.

[2] L. K. Larsen, "Tools and Techniques to Minimize Shock and Vibration to the Bottom Hole Assembly", 2014.

[3] G. P. G. Sotomayor, J. C. Plácido, and J. C. Cunha, "Drill string vibration: How to identify and suppress", SPE Lat. Am. Caribb. Pet. Eng. Conf. Proc., vol. 1997-Augus, pp. 1-11, 1997, doi: 10.2523/39002-ms.

[4] W. C. Maurer, "The 'Perfect - Cleaning' Theory of Rotary Drilling", J. Pet. Technol., vol. 14, no. 11, pp. 1270-1274, Nov. 1962, doi: 10.2118/408-pa.

[5] M. G. Bingham, "A New Approach to Interpreting Rock Drillability", Pet. Pub. Co. Houston, TX, USA, 1965.

[6] A. T. Bourgoyne and F. S. Young, "A multiple regression approach to optimal drilling and abnormal pressure detection", SPE Repr. Ser., vol. 4, no. 49, pp. 27-36, 1999, doi: 10.2118/4238-pa.

[7] A. Esmaeili, B. Elahifar, R. K. Fruhwirth, and G. Thonhauser, "ROP modeling using neural network and drill string vibration data", Soc. Pet. Eng. - Kuwait Int. Pet. Conf. Exhib. 2012, KIPCE 2012 People Innov. Technol. to Unleash Challenging Hydrocarb. Resour., vol. 2, pp. 537-549, 2012, doi: 10.2118/163330-ms.

[8] S. Elkatatny, "Application of Artificial Intelligence Techniques to Estimate the Static Poisson's Ratio Based on Wireline Log Data", J. Energy Resour. Technol. Trans. ASME, vol. 140, no. 7, 2018, doi: 10.1115/1.4039613.

[9] R. Wiśniowski, D. Knez, and Ł. Hytroś, "Drillability and Mechanical Specific Energy analysis on the example of drilling in the Pomeranian Basin", AGH Drilling, Oil, Gas, vol. 32, no. 1, p. 201, 2015, doi: 10.7494/drill.2015.32.1.201.

[10] S. Lek and J. F. Guégan, "Artificial neural networks as a tool in ecological modelling, an introduction", Ecol. Modell., vol. 120, no. 2-3, pp. 65-73, 1999, doi: 10.1016/S03043800(99)00092-7.

[11] H. B. Demuth, M. H. Beale, O. De Jess, and M. T. Hagan, Neural Network Design, 2nd ed. Stillwater, OK, USA: Martin Hagan, 2014.

[12] A. Hashemi Fath, F. Madanifar, and M. Abbasi, "Implementation of multilayer perceptron (MLP) and radial basis function (RBF) neural networks to predict solution gas-oil ratio of crude oil systems", Petroleum, vol. 6, no. 1, pp. 80-91, Mar. 2020, doi: 10.1016/j.petlm.2018.12.002.

[13] A. ElGibaly and M. Abdalla Osman, "Perforation friction modeling in limited entry fracturing using artificial neural network", Egypt. J. Pet., vol. 28, no. 3, pp. 297-305, Sep. 2019, doi: 10.1016/j.ejpe.2019.08.001.

[14] B. Zhou et al., "Relative Importance Analysis of a Refined Multi-parameter Phosphorus Index Employed in a Strongly Agriculturally Influenced Watershed", Water, Air, Soil Pollut., vol. 226, no. 3, p. 25, 2015, doi: 10.1007/s11270-014-2218-0.

[15] A. A. Elgibaly and A. M. Elkamel, "A new correlation for predicting hydrate formation conditions for various gas mixtures and inhibitors", Fluid Phase Equilib., vol. 152, no. 1, pp. 23-42, 1998, doi: 10.1016/S0378-3812(98)00368-9.

[16] C. F. Cunningham, L. Cooley, G. Wozniak, and J. Pancake, "Using multiple linear regression to model EURs of horizontal Marcellus shale wells", SPE East. Reg. Meet., pp. 223-243, 2012, doi: $10.2118 / 161343-\mathrm{ms}$. 
Figures

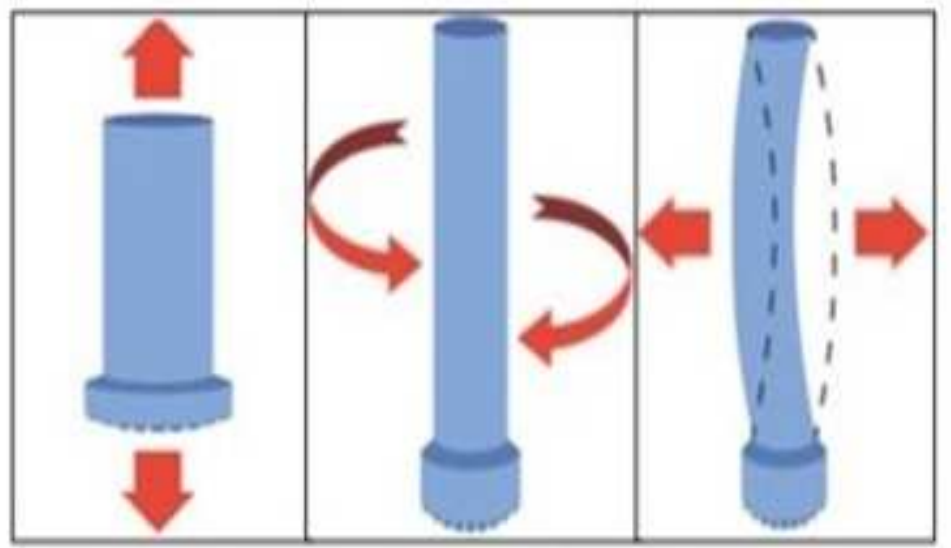

a) Axial vibration b) Torsional vibration c) Lateral vibration

Figure 1

Vibration modes a) Axial vibration b) Torsional vibration c) Lateral vibration

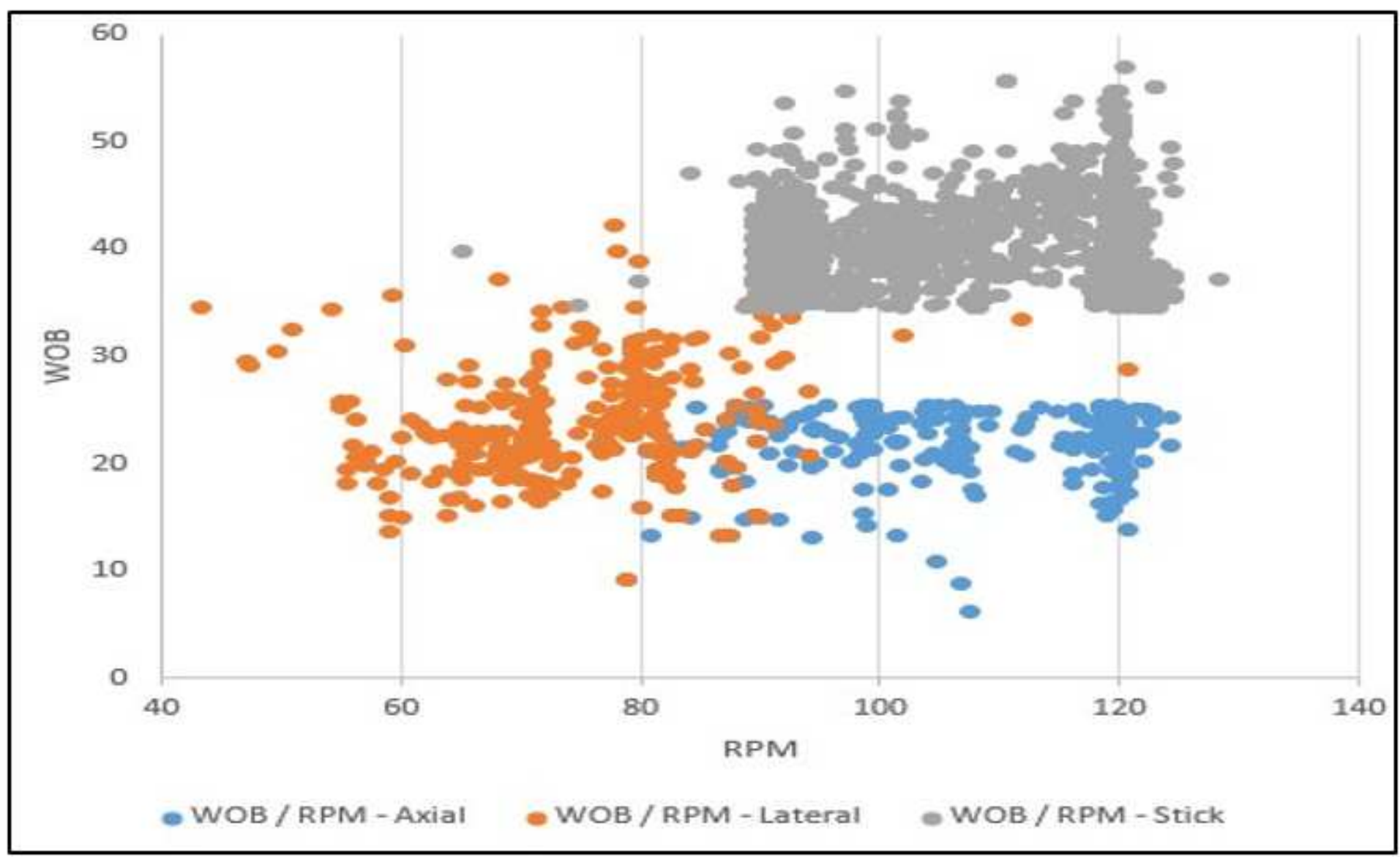

Figure 2

WOB / RPM relationship 


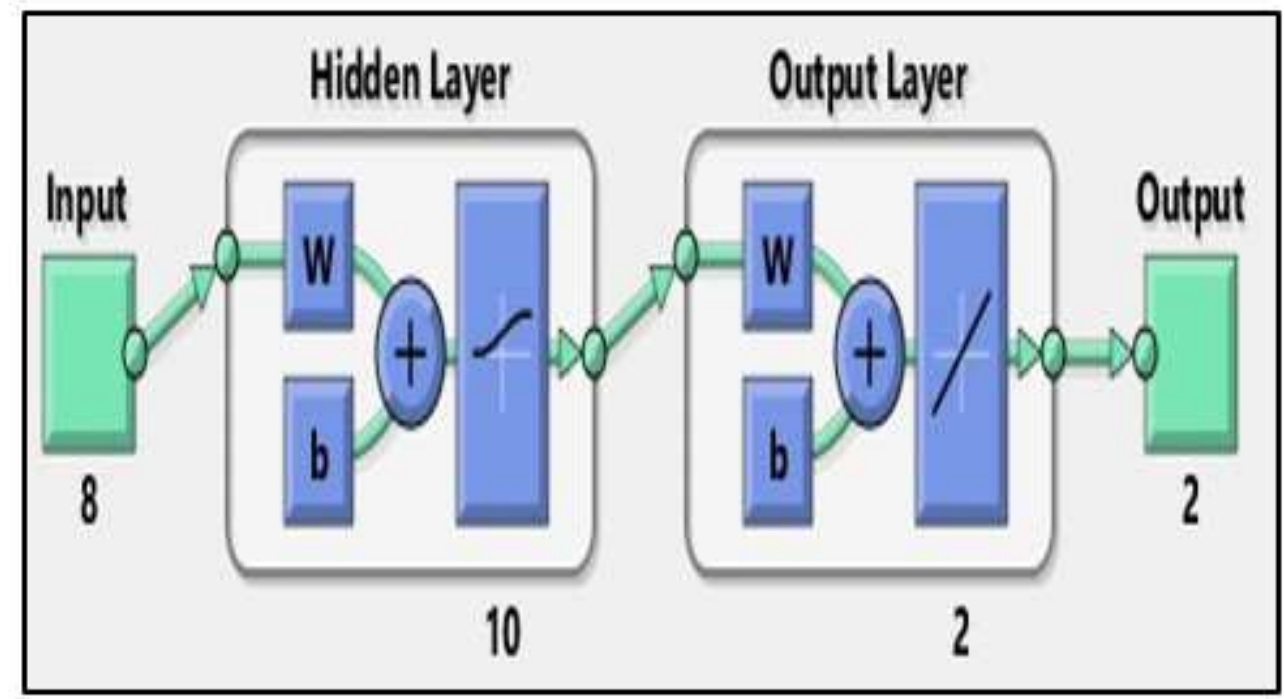

Figure 3

Axial proposed ANN model architecture (Generated by MATLABTM)

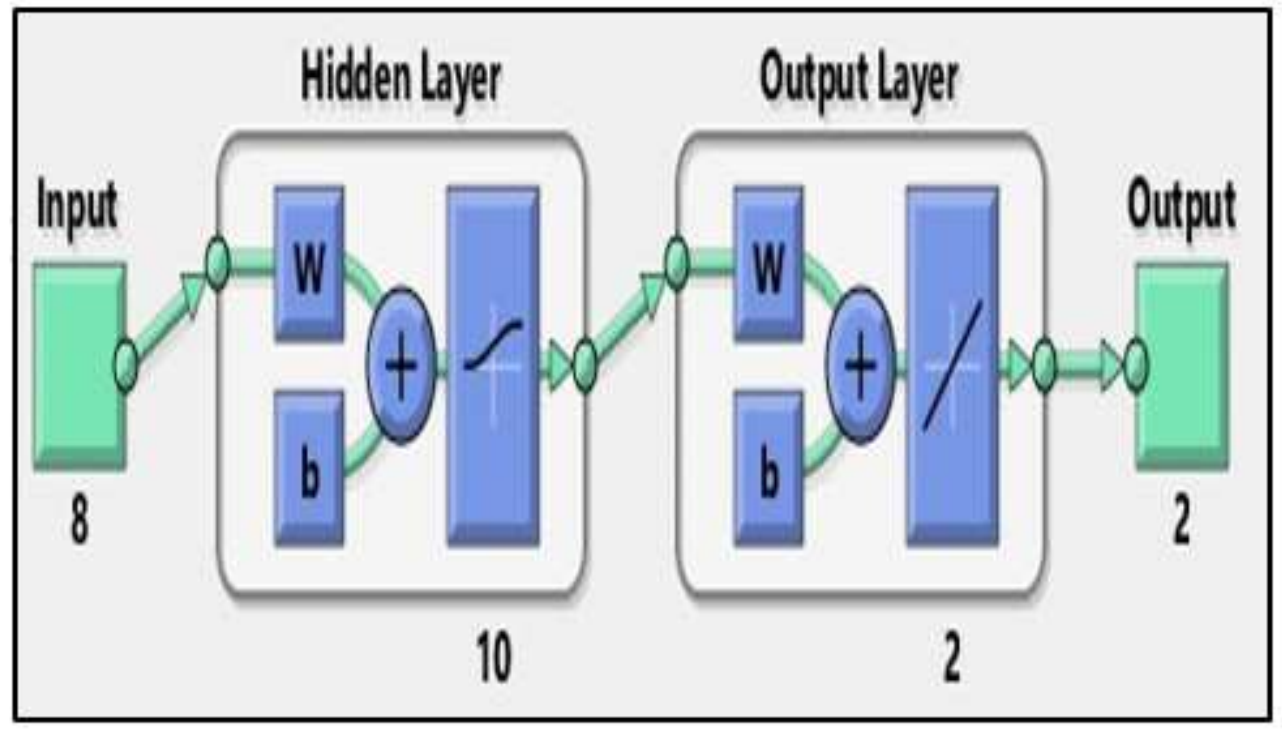

Figure 4

Lateral proposed ANN model architecture (Generated by MATLABTM) 


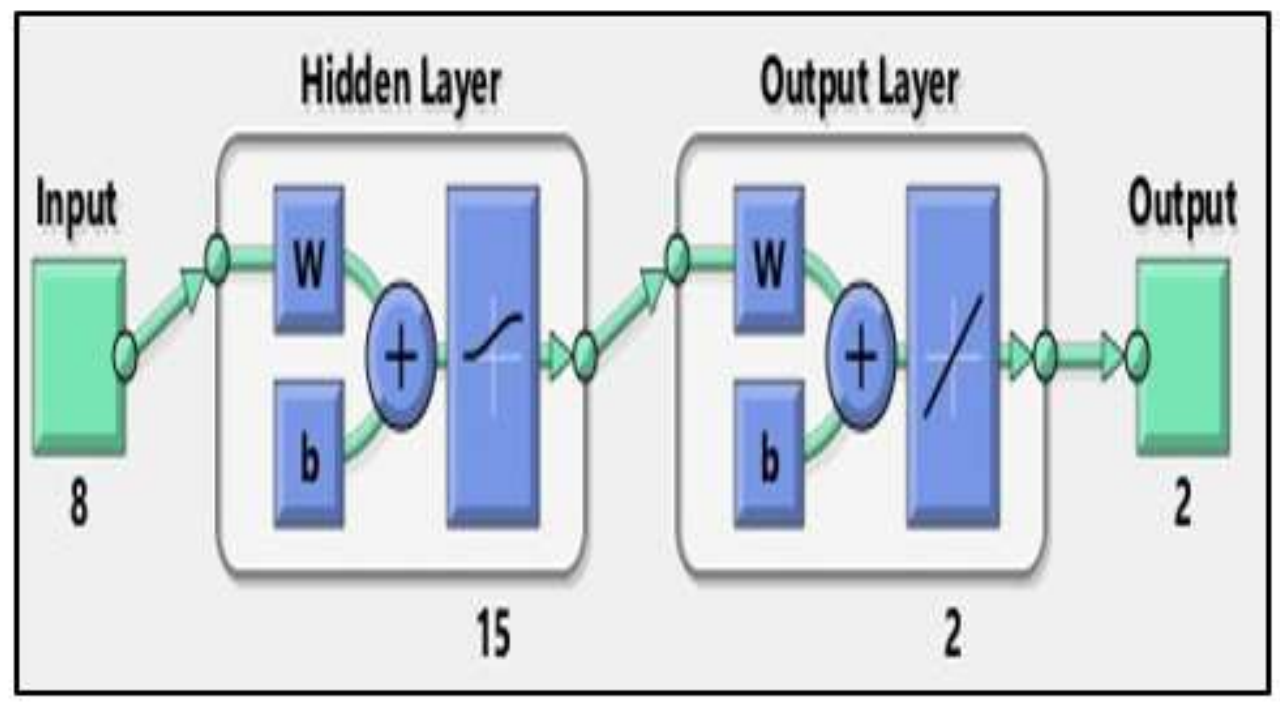

Figure 5

Stick-slip proposed ANN model architecture (Generated by MATLABTM)
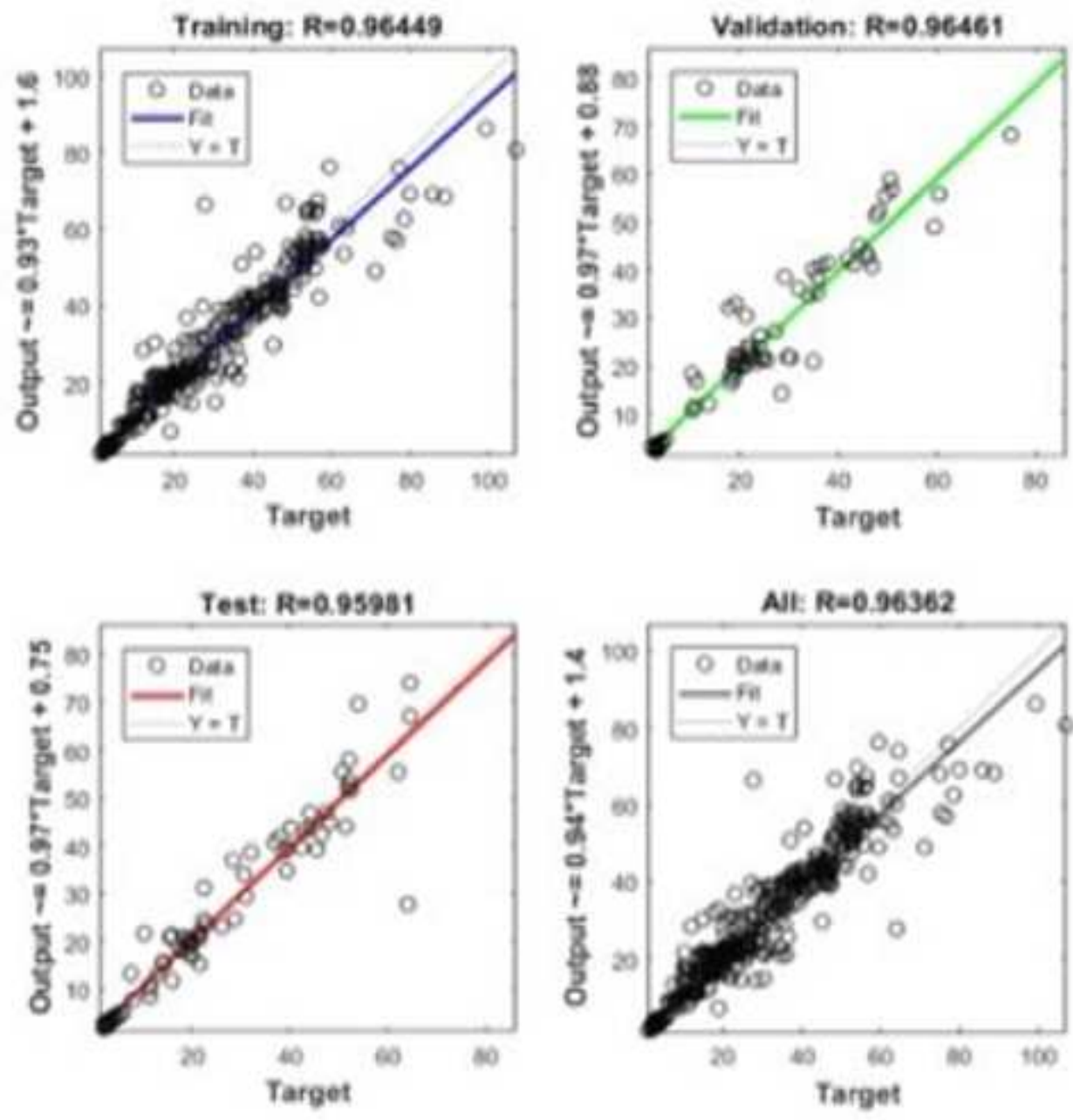

Figure 6 
Regression for Axial proposed ANN model (Generated by MATLABTM)
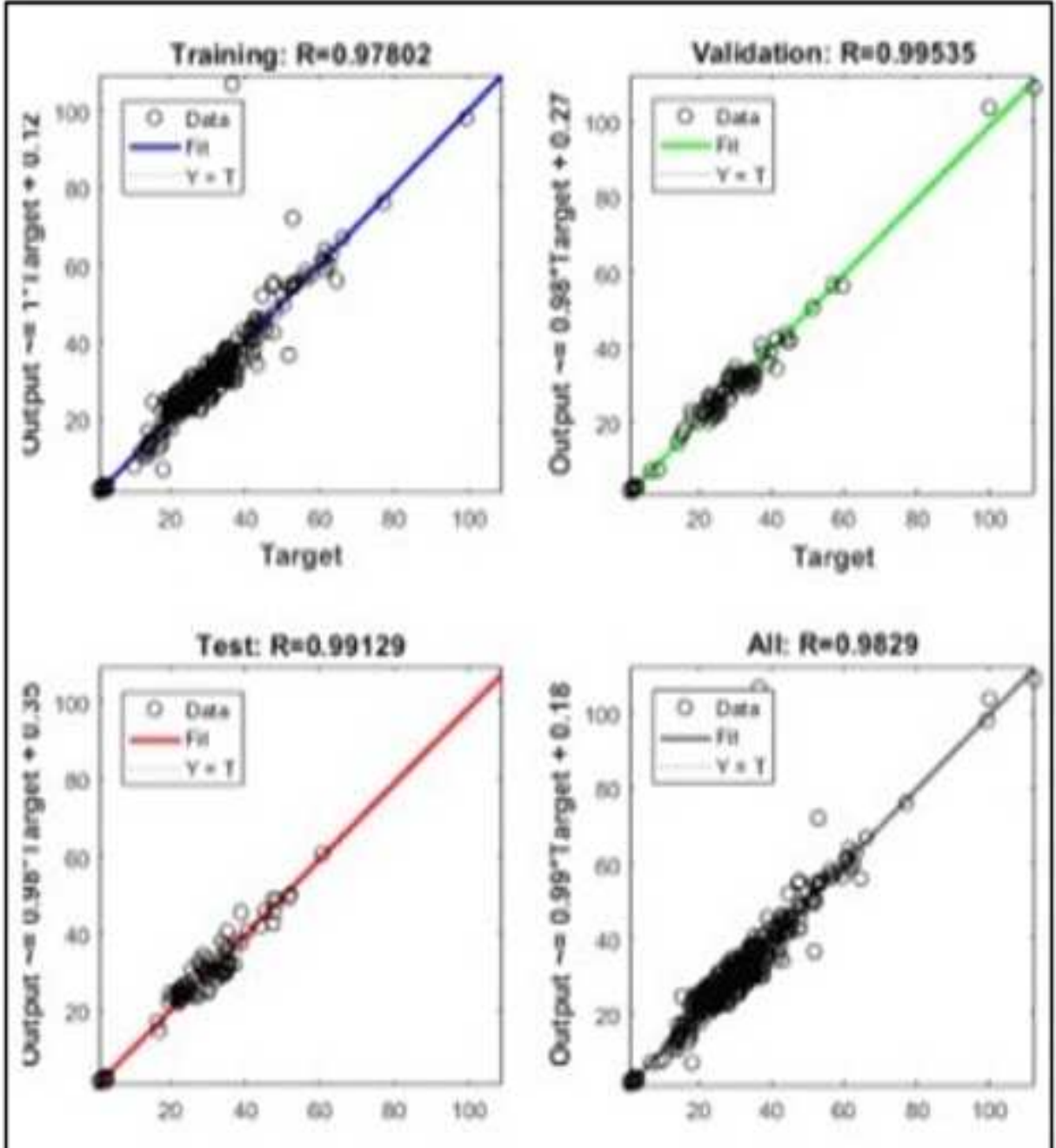

Figure 7

Regression for Lateral proposed ANN model (Generated by MATLABTM)
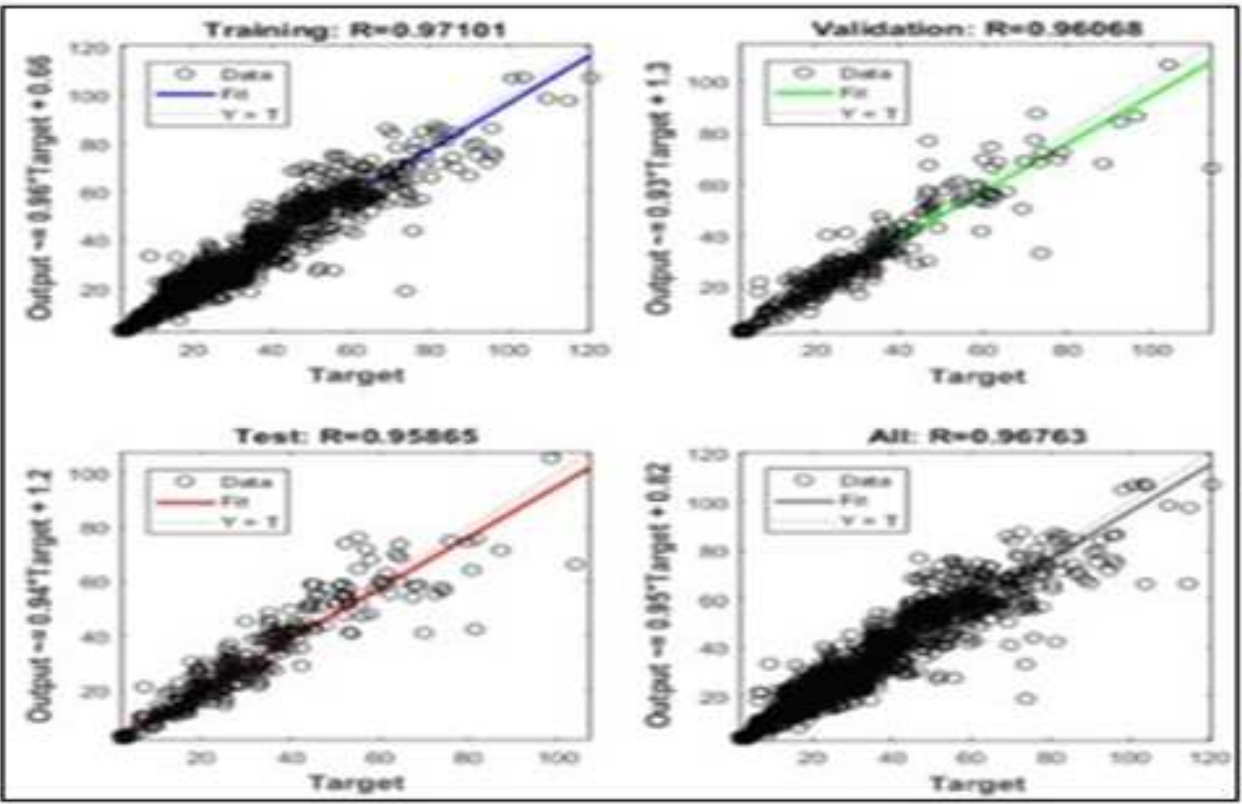
Figure 8

Regression for Stick-slip proposed ANN model (Generated by MATLABTM)

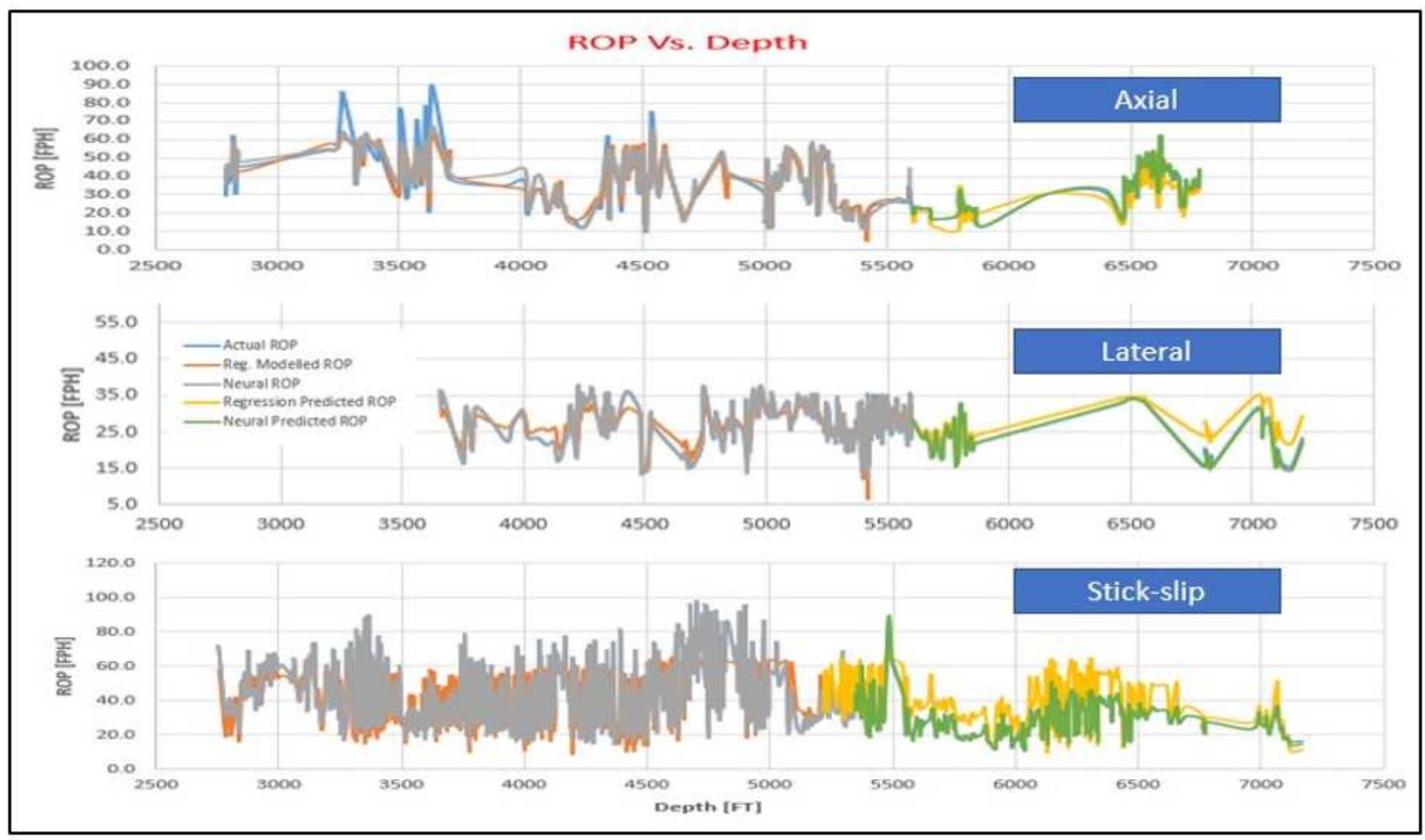

Figure 9

ROP neural, regression and actual vs. depth 


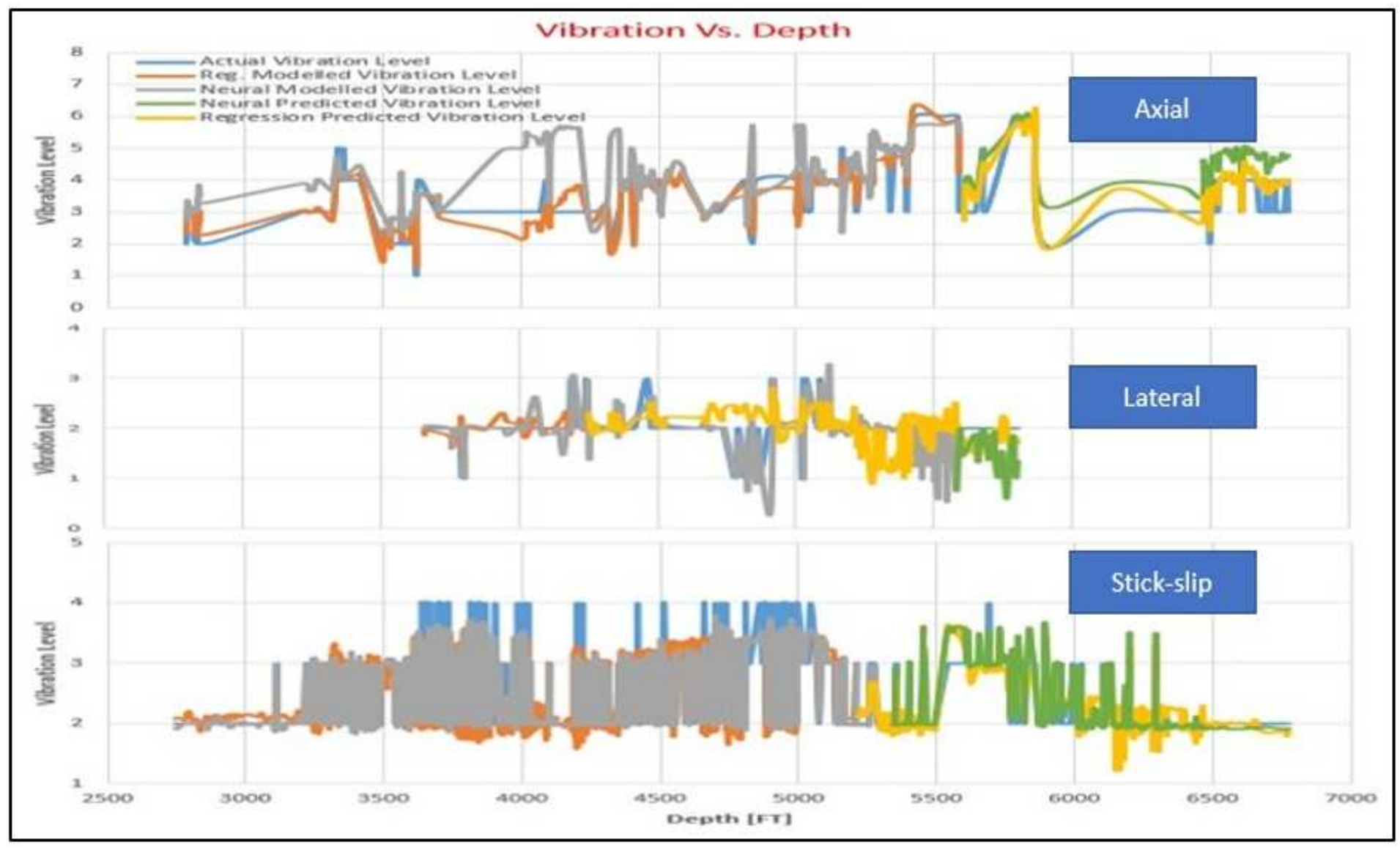

Figure 10

Vibration neural, regression and actual vs. depth

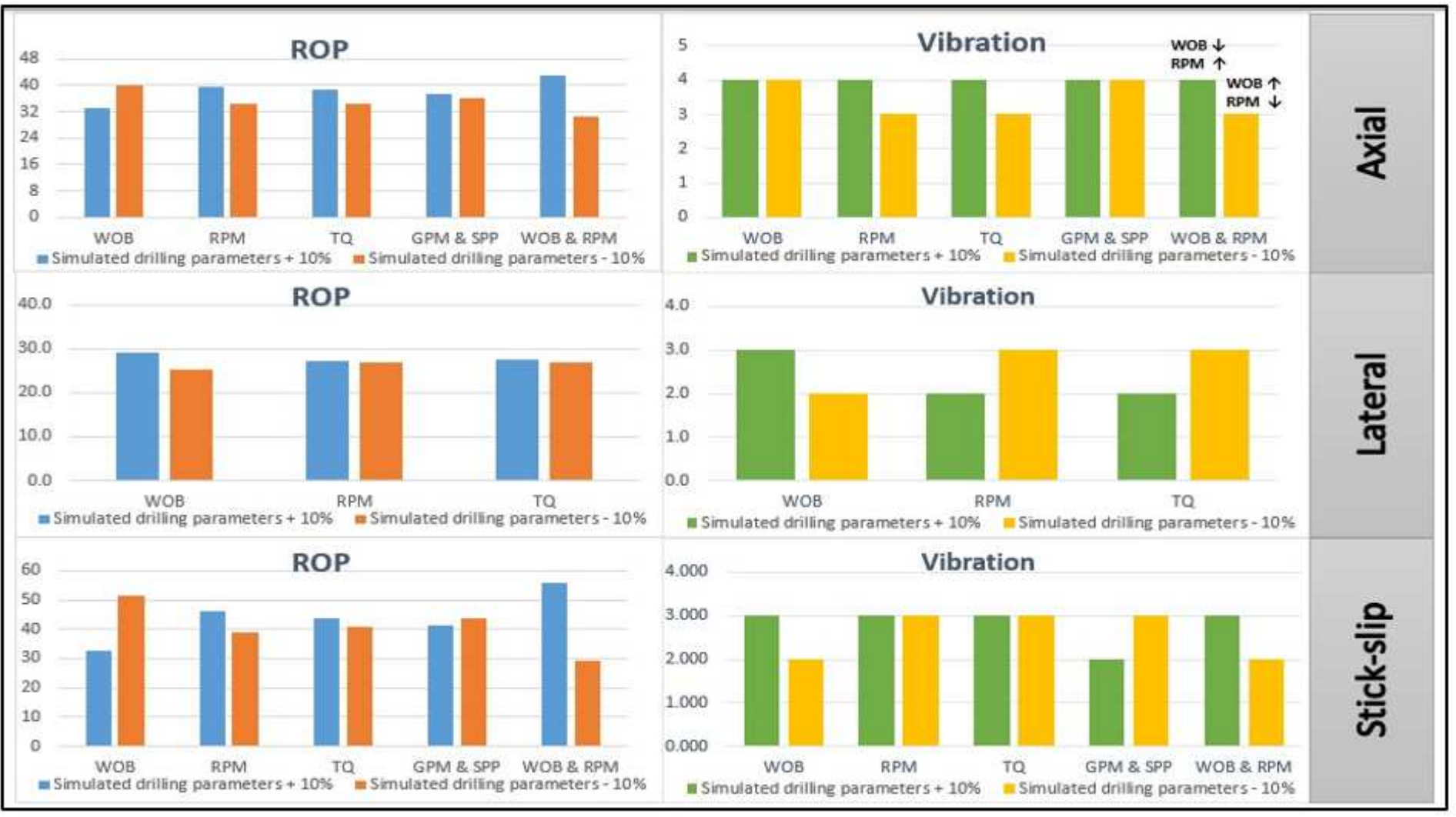


Figure 11

ROP and vibration parametric sensitivity analysis 